\title{
ESTABILIDADE DE AGREGADOS DO SOLO APÓS MANEJO COM ROTAÇÕES DE CULTURAS E ESCARIFICAÇÃO ${ }^{(1)}$
}

\author{
Juliano Carlos Calonego ${ }^{(2)} \&$ Ciro Antonio Rosolem ${ }^{(3)}$
}

\begin{abstract}
RESUMO
O objetivo desse trabalho foi avaliar, em solo compactado, a estabilidade dos agregados influenciada pelo cultivo de espécies de cobertura em esquema de rotações de culturas, em sistema de semeadura direta, mediante o efeito da escarificação mecânica. As rotações de culturas repetidas por três anos consecutivos envolveram o cultivo de triticale e girassol, no outono-inverno, associados ao cultivo de milheto, de sorgo forrageiro e de Crotalária júncea como plantas de cobertura, antecedendo o da soja (cultura de verão). No tratamento envolvendo a escarificação mecânica, a área permaneceu em pousio entre os cultivos de outono-inverno e de verão. O experimento foi realizado na Fazenda Experimental Lageado (Botucatu-SP), nos anos agrícolas de 2003/2004, 2004/2005 e 2005/2006. O delineamento experimental foi o de blocos ao acaso, com quatro repetições, em esquema de parcelas subdivididas. As amostras para a análise da estabilidade de agregados foram coletadas nas profundidades de 0 a $0,05 \mathrm{~m}$ e de 0,05 a 0,10 m após o manejo das plantas de cobertura em dezembro de 2003 e de 2005. Logo no primeiro ano de instalação do experimento, o cultivo de triticale resultou em maior porcentagem de agregados com mais de $2 \mathrm{~mm}$, maior DMG e maior DMP na camada de 0 a $5 \mathrm{~cm}$, além de maior DMP na camada de 0,05 a $0,10 \mathrm{~m}$. Já a escarificação do solo e a ausência do cultivo de plantas de cobertura proporcionaram menor porcentagem de agregados maiores que $2 \mathrm{~mm}$ e menor DMP na camada de 0,05 a $0,10 \mathrm{~m}$. A estabilidade dos agregados foi influenciada pela rotação de culturas, sendo maior na camada de 0 a $0,05 \mathrm{~m}$ e de 0,05 a $0,10 \mathrm{~m}$ quando o triticale foi introduzido como espécie de outono-inverno.
\end{abstract}

Termos de indexação: plantas de cobertura, semeadura direta, descompactação do solo.

(1) Parte da Tese de Doutorado do primeiro autor apresentada à Faculdade de Ciências Agronômicas, Universidade Estadual Paulista - FCA/UNESP. Recebido para publicação em agosto de 2007 e aprovado em abril de 2008.

(2) Professor Doutor, Faculdade de Agronomia, Centro de Ciências Agrárias, Universidade do Oeste Paulista - UNOESTE. Rodovia Raposo Tavares, km 572, CEP 19.067-175 Presidente Prudente (SP). E-mail: juliano@unoeste.br

(3) Professor Titular do Departamento de Produção Vegetal, Faculdade de Ciências Agronômicas, Universidade Estadual Paulista - FCA/UNESP. Campus de Botucatu, Caixa Postal 237, CEP 18603-970 Botucatu (SP). Bolsista do CNPq. E-mail: rosolem@fca.unesp.br 


\title{
SUMMARY: SOIL AGGREGATE STABILITY AFTER MANAGEMENT WITH CROP ROTATION AND CHISELING
}

\begin{abstract}
The objective of this study was to compare, in compacted soil condition, the aggregate stability after different crops rotations under no-tillage system and chiseling. The following crop rotations were repeated for three consecutive years under no-tillage: triticale $(X$ Triticosecale Wittmack) and sunflower (Helianthus annus) as autumn-winter crops, together with pearl millet (Pennisetum glaucum), forage sorghum (Sorghum bicolor) and sunn hemp (Crotalaria juncea) in spring, preceeding soybean (summer crop). In the chiseling treatment the area was kept bare between the autumn-winter and the summer crops. The study was carried out in three growing seasons (2003/2004, 2004/2005 and 2005/2006), in Botucatu, state of São Paulo, Brazil. The experiment had a complete randomized block design with split-plot and four replications. The samples for aggregate stability analysis were collected in the layers $0-5$ and 5-10 cm after cover crop desiccation, in the first and third year of the experiment. In the first year of the experiment, triticale resulted in a higher percentage of aggregates larger than $2 \mathrm{~mm}$, higher Mean Geometric Diameter and Mean Weight Diameter (MWD) of aggregates at the depth of $0-5 \mathrm{~cm}$, and higher $M W D$ at 5-10 cm. Chiseling and absence of cover crops reduced the percentage of aggregates larger than $2 \mathrm{~mm}$ and MWD values at 5-10 cm. Aggregate stability is influenced by crop rotation, and was highest in the layers $0-5$ and 5-10 cm when triticale was used as autumn-winter species.
\end{abstract}

Index terms: cover crops, no-tillage, soil decompaction.

\section{INTRODUÇÃO}

Em sistema semeadura direta (SSD), o rompimento da camada compactada do solo pode ser promovido por processos mecânicos e/ou biológicos. No método mecânico, dá-se preferência para equipamentos com hastes, pois operam abaixo da camada compactada, possuem menor superfície de contato e apresentam menor desagregação e mobilização do solo, mantendo grande parte das vantagens promovidas pelo SSD (Vernetti Júnior \& Gomes, 1999). Benefícios importantes têm sido observados na estruturação do solo, em médio e longo prazos, com a utilização de plantas de cobertura com alto potencial de fixação de carbono e que possuem sistema radicular volumoso e agressivo (Hakansson et al., 1988).

Considerado um manejo conservacionista, os escarificadores são equipamentos preferencialmente indicados para a descompactação mecânica, devido à formação de fissuras com mínima mobilização do solo. Isso mantém grande parte da cobertura morta e tem pequeno impacto nos teores de matéria orgânica (Torres et al., 1998), além de proporcionar alta rugosidade da superfície do terreno (Secco \& Reinert, 1997), reduzindo o escoamento superficial (Vasquez \& De Maria, 2003).

Nesse sentido, Torres \& Saraiva (1999) afirmaram que a melhoria das condições físicas do solo tem reflexos positivos na produtividade das culturas, porém o aumento da porosidade total promovida pela ação de implementos mecânicos de mobilização do solo e de rompimento da compactação não garante o maior crescimento das raízes, pois destrói a continuidade dos macroporos.
Entre os inconvenientes da escarificação mecânica, pode-se citar a necessidade de tratores de grande potência. Estima-se que, para cada haste do escarificador, sejam necessários em torno de $25 \mathrm{HP}$, constituindo uma operação onerosa com alto gasto de energia, consumindo em torno de $20 \mathrm{~L} \mathrm{ha}^{-1}$ de combustível (Kochhann et al., 2000). Além disso, com elevada quantidade de cobertura morta depositada na superfície do solo em SSD, podem ocorrer o arraste da palha e seu acúmulo em pontos do terreno, reduzindo o efeito protetor da palhada, além de dificultar a semeadura da cultura seguinte (Torres \& Saraiva, 1999).

Após a escarificação, caso não sejam tomadas medidas preventivas, como a utilização de plantas com sistema radicular abundante e que incremente o teor de MO para estabilizar os agregados do solo, a tendência é a acomodação das partículas do solo e, com o passar do tempo, a reconsolidação do solo (Kochhann et al., 2000). Segundo Araujo et al. (2004) e Busscher et al. (2002), apesar de positivos, há evidências de que os efeitos de escarificação são de curta duração.

Uma alternativa para melhorar a qualidade estrutural do solo refere-se ao uso de rotação de culturas com espécies que tenham sistema radicular vigoroso, com capacidade de crescer em solos com alta resistência à penetração, criando poros por onde as raízes da cultura subseqüente possam crescer (Silva \& Rosolem, 2001). Ehlers et al. (1983) também afirmam que em SSD os canais verticais contínuos servem como rotas, ligando a superfície do solo às camadas mais profundas, proporcionando maior colonização das raízes em profundidade. 
O maior crescimento de raízes no perfil do solo promove o aumento do teor de matéria orgânica (MO), que atuará na formação de agregados estáveis, pois a agregação do solo é condicionada por substâncias agregantes, ou seja, por substâncias que possuem ação cimentante e aglutinadora, como a matéria orgânica (Mielniczuk, 1999), que, em SSD, é incrementada em superfície pelo constante aporte de resíduos culturais, e em profundidade pela morte das raízes.

Os exsudados orgânicos liberados pelas raízes também possuem função cimentante das partículas do solo. Esse incremento dos compostos orgânicos, além do efeito direto na agregação do solo, serve de energia para a atividade microbiana, que libera moléculas orgânicas como subprodutos do metabolismo (ácidos húmicos e polissacarídeos), que também irão atuar como agentes aglutinadores dos grânulos minerais (Mielniczuk, 1999). Essas moléculas atuam na estabilidade dos agregados pelas ligações de polímeros orgânicos com superfície inorgânica por meio de cátions polivalentes (Castro Filho et al., 1998).

A agregação do solo também pode ter seu efeito acelerado pela exploração radicular no perfil do solo, que, no processo de crescimento, promove a aproximação das partículas à medida que as raízes exercem pressão sobre as partículas minerais no seu avanço pelo espaço poroso. A absorção de água pelas raízes também causa secamento na região adjacente às raízes, promovendo aumento na força de coesão entre as partículas (Zonta et al., 2006).

Nesse contexto, a proposta deste trabalho foi verificar, em um período de três anos, a estabilidade de agregados de um Nitossolo Vermelho, após o manejo da compactação do solo pelo método mecânico, por meio de escarificação, comparando com resultados obtidos com o cultivo de diferentes rotações de culturas envolvendo plantas de cobertura em SSD.

\section{MATERIAL E MÉTODOS}

O experimento foi realizado na Fazenda Experimental Lageado da FCA/Unesp, em BotucatuSP, nos anos agrícolas de 2003/2004, 2004/2005 e 2005/ 2006. O solo da área experimental foi classificado como Nitossolo Vermelho distroférrico de textura argilosa (Embrapa, 1999), conduzido a partir de 1997 em SSD com a rotação soja/aveia-preta/milho/triticale.

A localização geográfica dessa área está definida pelas seguintes coordenadas: latitude $22^{\circ} 49^{\prime} \mathrm{S}$, longitude $48^{\circ} 25^{\prime}$ WGrw, e altitude de $786 \mathrm{~m}$. O clima da região, segundo classificação de Köppen, é do tipo CWa, que significa clima mesotérmico com inverno seco. A estação seca é bem definida e ocorre entre os meses de maio a setembro. A precipitação média anual é de aproximadamente $1.400 \mathrm{~mm}$, com temperatura média do mês mais quente superior a $22{ }^{\circ} \mathrm{C}$ e a do mês mais frio entre 3 e $18{ }^{\circ} \mathrm{C}$.
Antes de iniciar o experimento, em abril de 2003, foi aberta uma trincheira de $1 \mathrm{~m}$ de profundidade para exposição do perfil do solo, onde observou-se uma camada mais compactada entre 0,05 e $0,20 \mathrm{~m}$ de profundidade. Em seguida, fizeram-se amostragens de solo para análise dos atributos químicos (Raij et al., 2001) e físicos (Embrapa, 1997) da área experimental (Quadro 1), além do teste de resistência mecânica à penetração (RP) ao longo do perfil, utilizando o penetrógrafo eletrônico com célula de carga desenvolvido por Santos \& Lanças (1999).

Os tratamentos foram constituídos pelas espécies graníferas triticale (X Triticosecale Wittmack) e girassol (Helianthus annuus) cultivadas no outonoinverno, combinadas com espécies de cobertura milheto (Pennisetum glaucum L., var. BN-2), sorgo forrageiro (Sorghum bicolor (L.) Moench) e Crotalária júncea (Crotalaria juncea L.), cultivadas na primavera, antecedendo a cultura de verão (soja - Glycine max L. (Merril), var. Embrapa 48), além do manejo do solo com escarificador.

Utilizou-se o delineamento experimental em blocos ao acaso, em um esquema de parcelas subdivididas, com quatro repetições. Foram consideradas parcelas aquelas cultivadas com triticale e girassol, e subparcelas as cultivadas com milheto, sorgo forrageiro e crotalária júncea, e também as escarificadas mecanicamente. A soja foi cultivada como safra de verão em todas as parcelas. Essa seqüência de cultivo foi repetida nas safras de 2003/ $2004,2004 / 2005$ e 2005/2006. A escarificação do solo foi realizada apenas em uma ocasião, ou seja, após a colheita das culturas de outono-inverno no primeiro ano (Setembro de 2003), mantendo a área escarificada sempre em pousio entre os cultivos de inverno e de verão.

Cada parcela experimental foi demarcada com uma área útil de $256 \mathrm{~m}^{2}$ (dimensões: 32 x $8 \mathrm{~m}$ ). $\mathrm{O}$ tamanho da parcela proporcionou a instalação de 16 linhas de semeadura de girassol, com um espaçamento entrelinhas de 0,51 m, e 47 linhas de semeadura de triticale, com um espaçamento entrelinhas de $0,17 \mathrm{~m}$. Nas subparcelas, a área útil foi de $40 \mathrm{~m}^{2}$ (dimensões: 8 x $5 \mathrm{~m}$ ), sendo possível a semeadura de 29 linhas de milheto, sorgo e crotalária, com um espaçamento entrelinhas de 0,17 m. Já a soja foi semeada em área total com um espaçamento entrelinhas de $0,45 \mathrm{~m}$ sobre os restos vegetais das plantas de cobertura e na área escarificada sem cultivo de primavera.

Para a semeadura de todas as culturas, utilizouse a semeadora equipada com discos de corte de palha com 16" de diâmetro e com discos sulcadores defasados (13" e 14" de diâmetro) para as sementes. A adubação da soja com fósforo e potássio seguiu recomendações específicas para a cultura de acordo com Raij et al. (1996). O girassol e o triticale foram cultivados sem fornecimento de fertilizantes, aproveitando a adubação residual dos cultivos anteriores. Já as plantas de cobertura receberam por ocasião da semeadura $40 \mathrm{~kg} \mathrm{ha}^{-1}$ de $\mathrm{N}$ na forma de uréia. 
Quadro 1. Propriedades químicas e físicas do solo da área experimental

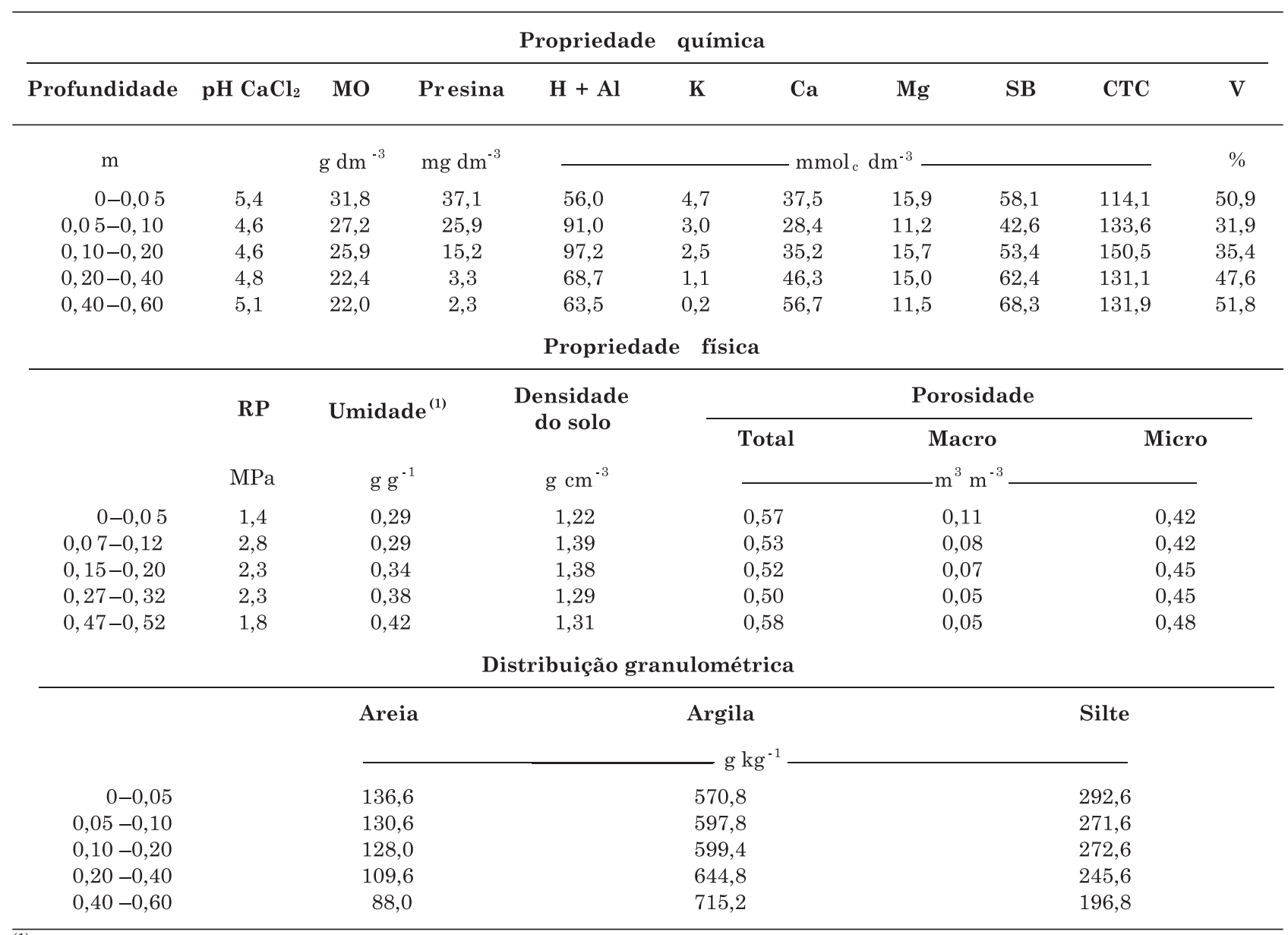

(1) Umidade gravimétrica do solo no momento do teste de resistência à penetração.

O manejo mecânico da compactação do solo foi realizado em setembro de 2003 utilizando um arado escarificador com sete hastes, montados em duas barras paralelas sobre um quadro porta-ferramentas. As hastes, inclinadas para frente formando um ângulo em torno de 20 a $25^{\circ}$, foram posicionadas espaçadas entre si de $0,60 \mathrm{~m}$, em cada barra, resultando em um espaçamento efetivo entre sulcos de $0,30 \mathrm{~m}$, com profundidade máxima de ação de $0,30 \mathrm{~m}$. Essa operação foi efetuada com o solo apresentando consistência friável. Acoplado ao equipamento foi colocado um rolo destorroador para quebrar os torrões maiores, diminuindo a rugosidade do terreno e eliminando a necessidade de realização de gradagem.

Logo após a realização do manejo mecânico, determinou-se novamente a RP em área escarificada e não escarificada, utilizando o penetrógrafo manual modelo "PENETROGRAPHER ${ }^{\text {PAT }}$ SC-60" para verificar o efeito da escarificação na descompactação do solo. As médias dos valores de resistência à penetração ao longo do perfil do solo estão apresentadas na figura 1.
Para a avaliação da estabilidade de agregados, foram coletadas quatro amostras de solo por parcela, com o auxílio de uma espátula, retirando torrões com

RESISTÊNCIA À PENETRAÇÃO, MPa

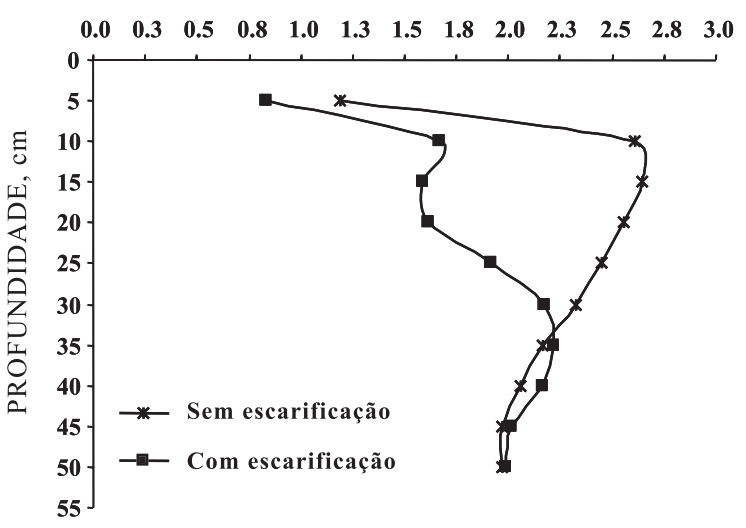

Figura 1. Resistência mecânica à penetração no perfil do solo em áreas com e sem manejo com escarificador. 
dimensões aproximadas de 0,05 $\mathrm{m}$ de altura por $0,15 \mathrm{~m}$ de comprimento e $0,10 \mathrm{~m}$ de largura, nas profundidades de 0-0,05 e 0,05-0,10 m. As amostras foram coletadas após o manejo químico das espécies de cobertura no primeiro e no terceiro ano do experimento (antes da semeadura da soja), ou seja, em dezembro de 2003 (primeira avaliação) e de 2005 (segunda avaliação). As amostras foram acondicionadas em sacos plásticos e posteriormente pré-selecionadas em um jogo de peneiras sobrepostas, tendo as peneiras superior e inferior malhas de 8 e $4 \mathrm{~mm}$, respectivamente. Para a avaliação da estabilidade dos agregados utilizou-se a porção que passou pela malha de $8 \mathrm{~mm}$ e ficou retida na de $4 \mathrm{~mm}$.

Para avaliar a estabilidade de agregados via úmida foram usados $25 \mathrm{~g}$ de solo de cada amostra, que foram pré-umedecidos, conforme o princípio de umedecimento lento descrito por Kemper \& Chepil (1965). Depois desse pré-umedecimento, as amostras foram mantidas em repouso em temperatura ambiente por $10 \mathrm{~min}$. Em seguida, essas amostras foram colocadas no aparelho de oscilação vertical sobre um conjunto de peneiras de 2,00;1,00;0,50;0,25 e 0,105 $\mathrm{mm}$ de diâmetro, conforme descrito por Yoder (1936). Transcorridos $15 \mathrm{~min}$, as porções retidas em cada peneira foram transferidas para potes de alumínio com o auxílio de jatos de água, e secas em estufa a $105^{\circ} \mathrm{C}$ por um período de $24 \mathrm{~h}$ para posterior pesagem. A partir dos valores dessas massas e conhecendo os teores de umidade das amostras de solo submetidas ao tamisamento, foram calculados a porcentagem de agregados retidos na peneira de $2 \mathrm{~mm}$ (agregados $>2 \mathrm{~mm}$ ), o diâmetro médio ponderado (DMP) e o diâmetro médio geométrico (DMG), conforme descrito por Kemper \& Chepil (1965). Quanto maior for a porcentagem de agregados grandes, ou seja, retidos nas peneiras com malhas maiores, maior será o DMP. Já o DMG representa uma estimativa da classe de agregados de maior ocorrência.

Os valores de DMP e DMG foram calculados pelas equações 1 e 2 , respectivamente, propostas por Castro Filho et al. (1998):

$$
\mathrm{DMP}=\sum_{i=1}^{n}(\mathrm{xi} \cdot \mathrm{wi})
$$

sendo xi = diâmetro médio das classes de agregados; wi $=$ proporção de cada classe em relação ao total.

$$
\mathrm{DMG}=\left(\exp _{i=1}^{n}(\mathrm{wp} \cdot \log \mathrm{xi})\right) /\left(\sum_{i=1}^{n} \mathrm{wi}\right)
$$

sendo $\mathrm{wp}=$ peso dos agregados de cada classe $(\mathrm{g}) ; \mathrm{xi}=$ diâmetro médio das classes; wi = proporção de cada classe em relação ao total.

O solo que não foi utilizado para a análise de estabilidade de agregados foi seco ao ar, moído, peneirado e analisado para determinação do teor de matéria orgânica (MO), de acordo com Raij et al. (2001).
Os dados originais foram submetidos à análise de variância, e as médias foram comparadas estatisticamente pelo teste t, a $5 \%$.

\section{RESULTADOS E DISCUSSÃO}

De acordo com o quadro 2, não houve interação significativa entre o cultivo de outono-inverno e o manejo de primavera para as variáveis analisadas.

A primeira avaliação de estabilidade dos agregados (Quadro 3) revelou que o cultivo de triticale como espécie de outono-inverno resultou em maior porcentagem de agregados maiores que $2 \mathrm{~mm}$, maior DMG e maior DMP, na camada de 0 a 0,05 m, além de maior DMP na camada de 0,05 a 0,10 m, indicando melhor estruturação do solo com a utilização dessa gramínea. Quanto ao manejo de primavera, os resultados diferiram significativamente apenas na camada subsuperficial de 0,05 a $0,10 \mathrm{~m}$, revelando que a escarificação do solo e a ausência do cultivo de plantas de cobertura proporcionaram menor porcentagem de agregados maiores que $2 \mathrm{~mm}$ e menor DMP.

Os solos com agregados estáveis de maior tamanho são considerados solos estruturalmente melhores e mais resistentes ao processo erosivo, pois a agregação facilita a aeração do solo, as trocas gasosas e a infiltração de água, em função do aumento da macroporosidade entre os agregados, além de garantirem a microporosidade e a retenção de água dentro dos agregados (Dexter, 1988). Os agregados estáveis também aumentam a capacidade de o solo receber carga sem sofrer deformações plásticas irreversíveis, ou seja, aumentam a pressão de preconsolidação do solo (Letey, 1985; Dexter, 1991).

A ação mecânica das hastes do escarificador, apesar de não revolver o solo, promove a ruptura da estrutura do solo, que tem a ação desagregadora intensificada com a utilização do rolo destorroador, que quebra os torrões para diminuir a rugosidade do terreno e facilitar o processo de semeadura. Essa ação desagregadora foi maior em subsuperfície do que em superfície devido ao menor teor de matéria orgânica (Figura 2a), promovendo menor estabilidade dos agregados em comparação à camada de 0 a 0,05 m. Segundo Oliveira et al. (2004) e Castro Filho et al. (1998), há correlação altamente significativa entre o aumento no teor de MO e o aumento da estabilidade de agregados até $0,10 \mathrm{~m}$ de profundidade.

Na segunda avaliação de estabilidade dos agregados realizada após três anos do início do experimento (Quadro 4), constatou-se aumento no tamanho dos agregados em todos os tratamentos e nas duas camadas avaliadas, devido ao aporte ocorrido no teor de MO (Figura 2b), independente do manejo adotado. O cultivo de crotalária proporcionou diferenças significativas no teor de MO em relação ao manejo 
Quadro 2. Valores de F calculados pela análise de variância para os resultados de agregados maiores que 2 mm, DMP, DMG e matéria orgânica nas camadas de 0-0,05 e 0,05-0,10 m, nas duas épocas de avaliação do experimento

\begin{tabular}{|c|c|c|c|c|}
\hline Causas de variação & Agregados $>2 \mathbf{m m}^{(1)}$ & DMP ${ }^{(2)}$ & $\mathrm{DMG}^{(3)}$ & $\mathbf{M O}^{(4)}$ \\
\hline & \multicolumn{4}{|c|}{0 a $0,05 \mathrm{~m}$ - primeira avaliação } \\
\hline Cultivo de inverno (CI) & 5,57 * & $5,60 *$ & $5,71 *$ & $0,55 \mathrm{~ns}$ \\
\hline Manejo de primavera (MP) & $1,61 \mathrm{~ns}$ & $1,63 \mathrm{~ns}$ & $0,22 \mathrm{~ns}$ & $1,42 \mathrm{~ns}$ \\
\hline CI $x$ MP & $1,00 \mathrm{~ns}$ & $0,79 \mathrm{~ns}$ & $0,52 \mathrm{~ns}$ & $0,31 \mathrm{~ns}$ \\
\hline \multicolumn{5}{|l|}{ CV $(\%)$} \\
\hline Cultivo de inverno & 20,65 & 16,94 & 44,64 & 5,83 \\
\hline \multirow[t]{2}{*}{ Manejo de primavera } & 11,11 & 9,14 & 8,92 & 9,35 \\
\hline & \multicolumn{4}{|c|}{0,05 a $0,10 \mathrm{~m}$ - primeira avaliação } \\
\hline Cultivo de inverno (CI) & $1,02 \mathrm{~ns}$ & $0,52 \mathrm{~ns}$ & 4,45 * & $0,61 \mathrm{~ns}$ \\
\hline Manejo de primavera (MP) & $2,06 *$ & $2,21 *$ & $0,76 \mathrm{~ns}$ & $1,69 \mathrm{~ns}$ \\
\hline CI x MP & $0,84 \mathrm{~ns}$ & $0,76 \mathrm{~ns}$ & $0,36 \mathrm{~ns}$ & $2,06 \mathrm{~ns}$ \\
\hline \multicolumn{5}{|l|}{ CV (\%) } \\
\hline Cultivo de inverno & 15,07 & 12,31 & 57,63 & 5,38 \\
\hline \multirow[t]{2}{*}{ Manejo de primavera } & 17,29 & 11,02 & 24,21 & 8,93 \\
\hline & \multicolumn{4}{|c|}{0 a $0,05 \mathrm{~m}$ - segunda avaliação } \\
\hline Cultivo de inverno (CI) & 2,33 * & $2,42 \mathrm{~ns}$ & $0,68 \mathrm{~ns}$ & $0,01 \mathrm{~ns}$ \\
\hline Manejo de primavera (MP) & $0,38 \mathrm{~ns}$ & $0,41 \mathrm{~ns}$ & $1,03 \mathrm{~ns}$ & $2,32 *$ \\
\hline CI x MP & $0,49 \mathrm{~ns}$ & $0,48 \mathrm{~ns}$ & $0,85 \mathrm{~ns}$ & $0,91 \mathrm{~ns}$ \\
\hline \multicolumn{5}{|l|}{ CV $(\%)$} \\
\hline Cultivo de inverno & 15,28 & 14,03 & 7,55 & 4,01 \\
\hline \multirow[t]{2}{*}{ Manejo de primavera } & 6,14 & 5,79 & 8,47 & 11,51 \\
\hline & \multicolumn{4}{|c|}{0,05 a $0,10 \mathrm{~m}$ - segunda avaliação } \\
\hline Cultivo de inverno (CI) & $2,32 \mathrm{~ns}$ & $2,34 \mathrm{~ns}$ & $0,24 \mathrm{~ns}$ & $1,63 \mathrm{~ns}$ \\
\hline Manejo de primavera (MP) & $1,00 \mathrm{~ns}$ & $1,10 \mathrm{~ns}$ & $0,62 \mathrm{~ns}$ & $1,02 \mathrm{~ns}$ \\
\hline CI x MP & $2,54 \mathrm{~ns}$ & $2,80 \mathrm{~ns}$ & $2,45 \mathrm{~ns}$ & $0,73 \mathrm{~ns}$ \\
\hline Cultivo de inverno & 6,79 & 5,87 & 5,44 & 7,51 \\
\hline Manejo de primavera & 4,45 & 4,03 & 8,68 & 5,95 \\
\hline
\end{tabular}

(1) Agregados maiores que $2 \mathrm{~mm} .{ }^{(2)}$ Diâmetro médio ponderado. ${ }^{(3)}$ Diâmetro médio geométrico. ${ }^{(4)}$ Teor de matéria orgânica. Médias seguidas de letras diferentes na coluna diferem entre si pelo teste t a $5 \%$. ${ }^{\text {ns }} \mathrm{e}^{*}$ : não significativo e significativo a $5 \%$ pelo teste $\mathrm{F}$, respectivamente.

Quadro 3. Resultados da análise de estabilidade de agregados e do teor de matéria orgânica, referentes à primeira avaliação do experimento

\begin{tabular}{|c|c|c|c|c|}
\hline Tratamento & Agregados $>2 \mathrm{~mm}$ & $\mathbf{D M P}^{(3)}$ & $\mathrm{DMG}^{(4)}$ & $\mathbf{M O}^{(5)}$ \\
\hline & \multirow[t]{2}{*}{$\mathrm{g} \mathrm{g}^{-1}$} & \multicolumn{2}{|c|}{$\longrightarrow \mathrm{mm} \longrightarrow$} & $\mathrm{g} \mathrm{dm}^{-3}$ \\
\hline Cultivo de inverno $^{(1)}$ & & \multicolumn{3}{|c|}{0 a $0,05 \mathrm{~m}$} \\
\hline Girassol & $0,82 \mathrm{~b}$ & $4,18 \mathrm{~b}$ & $3,50 \mathrm{~b}$ & 32,3 \\
\hline $\begin{array}{l}\text { Triticale } \\
\text { Manejo de primavera }\end{array}$ & $0,88 \mathrm{a}$ & 4,43 a & $4,10 \mathrm{a}$ & 31,7 \\
\hline Milheto & 0,87 & 4,40 & 3,93 & 31,9 \\
\hline Sorgo & 0,88 & 4,42 & 3,83 & 31,6 \\
\hline Crotalária & 0,84 & 4,28 & 3,79 & 33,5 \\
\hline Escarificação & 0,80 & 4,12 & 3,64 & 31,1 \\
\hline Cultivo de inverno & \multicolumn{4}{|c|}{0,05 a $0,10 \mathrm{~m}$} \\
\hline Girassol & 0,79 & 4,09 & $3,08 \mathrm{~b}$ & 27,6 \\
\hline Triticale & 0,82 & 4,17 & 3,78 a & 27,42 \\
\hline \multicolumn{5}{|l|}{ Manejo de primavera } \\
\hline Milheto & $0,84 \mathrm{a}$ & 4,29 a & 3,65 & 26,2 \\
\hline Sorgo & $0,82 \mathrm{a}$ & $4,20 \mathrm{a}$ & 3,00 & 28,2 \\
\hline Crotalária & $0,80 \mathrm{a}$ & $4,10 \mathrm{a}$ & 3,50 & 27,7 \\
\hline Escarificação & $0,75 \mathrm{~b}$ & $3,91 \mathrm{~b}$ & 3,56 & 27,98 \\
\hline
\end{tabular}

(1) Médias seguidas de letras diferentes na coluna para os cultivos de inverno diferem entre si pelo teste $\mathrm{F}$ a $5 \%$. ${ }^{(2)}$ Médias seguidas de letras diferentes na coluna para os manejos de primavera diferem entre si pelo teste t a $5 \%$. ${ }^{(3)}$ Diâmetro médio ponderado. ${ }^{(4)}$ Diâmetro médio geométrico. ${ }^{(5)}$ Teor de matéria orgânica. 
com escarificador, não diferindo dos demais manejos de primavera. O menor teor de MO no tratamento

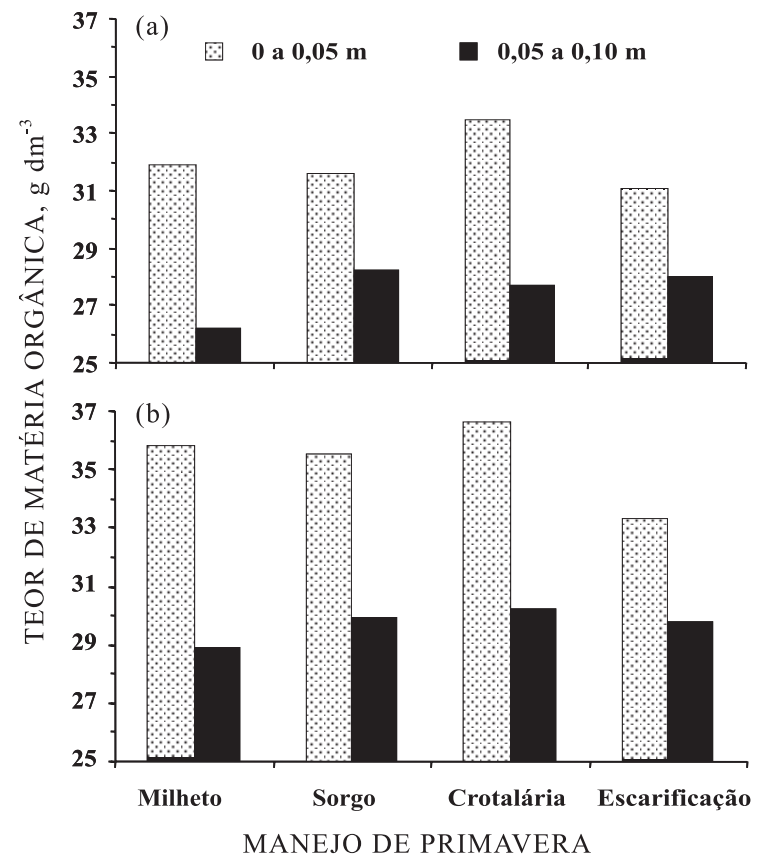

Figura 2. Teor de matéria orgânica do solo em função do manejo de primavera, referente às amostras coletadas antes do cultivo da soja na primeira (a) e na segunda (b) avaliação do experimento, nas camadas de 0 a $0,05 \mathrm{~m}$ e de 0,05 a $0,10 \mathrm{~m}$. envolvendo escarificação do solo está relacionando com o menor aporte de carbono, já que nesse manejo o solo ficou em pousio entre o cultivo de outono-inverno e de verão. No entanto, esse menor teor de MO na área escarificada não foi suficiente para ocasionar diferenças significativas na agregação do solo.

Bayer et al. (2003), comparando diferentes sistemas de rotação de culturas no SSD, com espécies de cobertura antecedendo o milho no verão, constataram que, em 5 anos, os estoques de C orgânico da camada arável do solo apresentaram incrementos expressivos nas áreas cultivadas com leguminosas de cobertura, em relação ao cultivo de milho após pousio. Portanto, a simples inclusão de culturas de cobertura proporcionou recuperações significativas dos estoques de $\mathrm{MO}$ do solo.

Comparando as culturas de outono-inverno no terceiro ano do experimento, observou-se que o triticale proporcionou maior porcentagem de agregados maiores que $2 \mathrm{~mm}$ na camada de 0 a $0,05 \mathrm{~m}$ (Quadro 4). Essas diferenças encontradas na estruturação do solo com o cultivo de triticale em relação ao girassol, tanto na primeira (Quadro 3) como na segunda avaliação do experimento (Quadro 4), podem ser explicadas pelo efeito que as raízes apresentam na agregação do solo.

Segundo Mielniczuk (1999), a maior densidade de raízes das monocotiledôneas em relação às dicotiledôneas e a distribuição mais uniforme do sistema radicular favorecem a distribuição dos exsudados no solo. Silva \& Mielniczuk (1997) afirmam que as gramíneas podem ser usadas como plantas

Quadro 4. Resultados da análise de estabilidade de agregados e do teor de matéria orgânica, referentes à segunda avaliação do experimento

\begin{tabular}{|c|c|c|c|c|}
\hline Tratamento & Agregados $>2 \mathrm{~mm}$ & $\mathbf{D M P}^{(3)}$ & $\mathrm{DMG}^{(4)}$ & MO $^{(5)}$ \\
\hline & $\mathrm{g} \mathrm{g}^{-1}$ & \multicolumn{2}{|c|}{$\longrightarrow \mathrm{mm}$} & $\mathrm{g} \mathrm{dm}^{-3}$ \\
\hline Cultivo de inverno $^{(1)}$ & \multicolumn{4}{|c|}{0 a $0,05 \mathrm{~m}$} \\
\hline Girassol & $0,91 \mathrm{~b}$ & 4,57 & 4,04 & 35,3 \\
\hline Triticale & $0,96 \mathrm{a}$ & 4,81 & 3,93 & 35,4 \\
\hline \multicolumn{5}{|l|}{ Manejo de primavera ${ }^{(2)}$} \\
\hline Milheto & 0,93 & 4,70 & 4,00 & $35,8 \mathrm{ab}$ \\
\hline Sorgo & 0,91 & 4,58 & 4,15 & $35,5 \mathrm{ab}$ \\
\hline Crotalária & 0,93 & 4,67 & 3,83 & 36,6 a \\
\hline Escarificação & 0,96 & 4,82 & 3,96 & $33,3 \mathrm{~b}$ \\
\hline Cultivo de inverno & \multicolumn{4}{|c|}{0,05 a $0,10 \mathrm{~m}$} \\
\hline Girassol & 0,94 & 4,74 & 4,13 & 29,4 \\
\hline Triticale & 0,96 & 4,83 & 4,05 & 29,8 \\
\hline \multicolumn{5}{|l|}{ Manejo de primavera } \\
\hline Milheto & 0,93 & 4,69 & 3,98 & 28,9 \\
\hline Sorgo & 0,96 & 4,85 & 4,24 & 29,9 \\
\hline Crotalária & 0,95 & 4,80 & 4,14 & 30,2 \\
\hline Escarificação & 0,95 & 4,80 & 3,99 & 29,8 \\
\hline
\end{tabular}

(1) Médias seguidas de letras diferentes na coluna para os cultivos de inverno diferem entre si pelo teste $\mathrm{F}$ a $5 \%$. ${ }^{(2)} \mathrm{Médias}$ seguidas de letras diferentes na coluna para os manejos de primavera diferem entre si pelo teste t a $5 \%$. ${ }^{(3)}$ Diâmetro médio ponderado. ${ }^{(4)}$ Diâmetro médio geométrico. ${ }^{(5)}$ Teor de matéria orgânica. 
recuperadoras da estrutura do solo em áreas degradadas, por apresentarem maior densidade de raízes e melhor distribuição do sistema radicular no solo, favorecendo as ligações dos pontos de contato entre partículas minerais e agregados, contribuindo para a formação e estabilidade dos agregados.

O maior efeito de raízes de monocotiledôneas em relação às dicotiledôneas na estruturação do solo foi constatado por Castro Filho et al. (1998). Os autores observaram que, com a rotação milho/trigo/milho, a estabilidade do solo, na profundidade de 0 a $0,10 \mathrm{~m}$, foi $20 \%$ superior comparada com a rotação soja/trigo/ soja.

Apesar de não haver diferenças significativas para a interação entre o cultivo de outono-inverno e o manejo de primavera, o efeito das espécies de monocotiledôneas na estruturação do solo está representado na figura $3 \mathrm{a}$. Na primeira avaliação do experimento, os tratamentos com ausência de espécies com sistema radicular fasciculado, como girassol/ crotalária e girassol/escarificação, proporcionaram menor quantidade de agregados com diâmetro superior a $2 \mathrm{~mm}$ na camada de 0 a $0,05 \mathrm{~m}$. Já o manejo em que a escarificação do solo foi feita em parcelas cultivadas com triticale, a descompactação do solo não proporcionou desagregação em superfície. O efeito benéfico do triticale na estabilidade dos agregados do

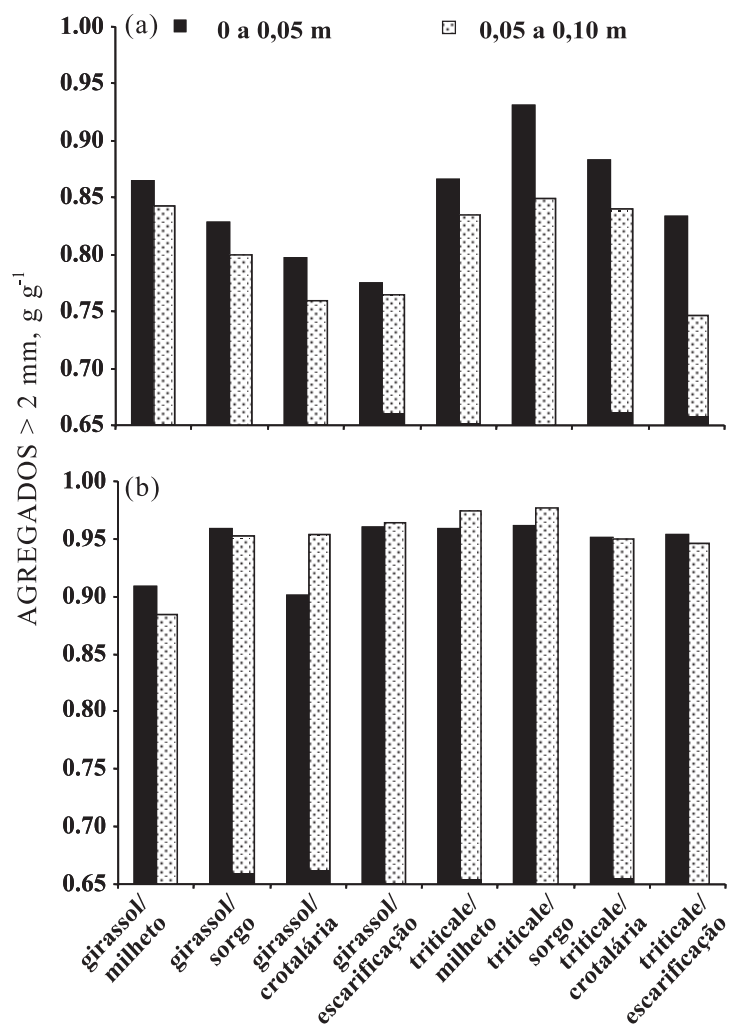

Figura 3. Agregados maiores que $2 \mathrm{~mm}$, nas camadas de 0 a $0,05 \mathrm{~m}$ e de 0,05 a $0,10 \mathrm{~m}$, na primeira (a) e, na segunda (b), avaliação do experimento. solo fica claro quando comparam-se os tratamentos girassol/crotalária e triticale/crotalária, em que a presença da espécie com sistema radicular fasciculado, como cultura de outono-inverno, proporcionou aumentos de, aproximadamente, $10 \%$ na quantidade de agregados maiores que $2 \mathrm{~mm}$ nas camadas de 0 0,05 e 0,05-0,10 m de profundidade.

Quanto aos resultados de estabilidade de agregados nas parcelas escarificadas, constatou-se que o efeito desagregador da descompactação mecânica, observado na primeira avaliação, principalmente na camada de 0,05 a $0,10 \mathrm{~m}$, foi recuperado apenas com o cultivo de outono-inverno e de verão por três anos consecutivos (Figura 3b), proporcionando agregados de tamanhos semelhantes aos obtidos com o cultivo de plantas de cobertura por três anos consecutivos.

\section{CONCLUSÕES}

1. A estabilidade dos agregados é influenciada pela rotação de culturas, sendo maior na camada de 0 a $0,05 \mathrm{~m}$ e de 0,05 a $0,10 \mathrm{~m}$ quando o triticale é introduzido como espécie de outono-inverno.

2. O manejo mecânico da compactação do solo com escarificador e ausência de plantas de cobertura antecedendo a soja promove redução da estabilidade dos agregados na camada de 0,05 a 0,10 m. Essa desestruturação do solo é recuperada com o cultivo de outono-inverno e de verão em SSD por três anos consecutivos.

\section{AGRADECIMENTOS}

À Fundação de Amparo à Pesquisa do Estado de São Paulo (FAPESP), pela concessão de bolsa de estudo ao primeiro autor.

\section{LITERATURA CITADA}

ARAUJO, M.A.; TORMENA, C.A.; INOUE, T.T. \& COSTA, A.C.S. Efeitos da escarificação na qualidade física de um Latossolo Vermelho distroférrico após treze anos de semeadura direta. R. Bras. Ci. Solo, 28:495-504, 2004.

BAYER, C.; SPAGNOLLO, E.; WILDNER, L.P.; ERNANI, P.R. \& ALBURQUEQUE, J.A. Incremento de carbono e nitrogênio num Latossolo pelo uso de plantas estivais para cobertura do solo. Ci. Rural, 33:469-475, 2003.

BUSSCHER, W.J.; BAUER, P.J. \& FREDERICK, J.R. Recompaction of a coastal loamy sand after deep tillage as a function of subsequent cumulative rainfall. Soil Till. Res., 68:49-57, 2002. 
CASTRO FILHO, C.; MUZILLI, O. \& PODANOSCHI, A.L. Estabilidade dos agregados e sua relação com o teor de carbono orgânico num Latossolo Roxo distrófico, em função de sistemas de plantio, rotações de culturas e métodos de preparo de amostras. R. Bras. Ci. Solo, 22:527$538,1998$.

DEXTER, A.R. Advances in characterization of soil structure. Soil Till. Res., 11:199-238, 1988.

DEXTER, A.R. Amelioration of soil by natural processes. Soil Till. Res., 20:87-100, 1991.

EHLERS, W.; KOPKE, V.; HESSE, F. \& BOHM, W. Penetration resistance and root growth of oats tilled and untilled loess soil. Soil Till. Res., 3:261-275, 1983.

EMPRESA BRASILEIRA DE PESQUISA AGROPECUÁRIA EMBRAPA. Centro Nacional de Pesquisa de Solos. Sistema brasileiro de classificação de solos. Rio de Janeiro, 1999. $412 \mathrm{p}$

EMPRESA BRASILEIRA DE PESQUISA AGROPECUÁRIA EMBRAPA. Serviço Nacional de Pesquisa do Solo. Manual de métodos de análises de solo. Rio de Janeiro, 1997. $212 \mathrm{p}$.

HAKANSSON, I.; VOORHEES, W.B. \& RILEY, H. Vehicle and wheel factors influencing soil compaction and crop response in different traffic regimes. Soil Till. Res., 11:239-282, 1988.

KEMPER, W.D. \& CHEPIL, W.S. Size distribution of aggregates. In: BLACK, C.A.; EVANS, D.D.; WHITE, J.L.; ENSMINGE, L.E. \& CLARK, F.E., eds. Methods of soil analysis. Madison, American Society of Agronomy, 1965. p.499-510.

KOCHHANN. R.A.; DENARDIN, J.E. \& BERTON, A.L Compactação e descompactação de solos. Passo Fundo, Embrapa Trigo, 2000. 20p. (Embrapa Trigo. Documentos, 19)

LETEY, J. Relationship between soil physical properties and crop productions. Adv. Soil Sci., 1:277-294, 1985.

MIELNICZUK, J. Matéria orgânica e sustentabilidade de sistemas agrícolas. In: SANTOS, G.A. \& CAMARGO, F.A.O., eds. Fundamentos da matéria orgânica do solo ecossistemas tropicais e subtropicais. Porto Alegre, Genesis, 1999. p.1-8.

OLIVEIRA, G.C.; DIAS JÚNIOR, M.S.; RESCKN, D.V.S. \& CURI, N. Caracterização química e físico-hídrica de um Latossolo Vermelho após vinte anos de manejo e cultivo do solo. R. Bras. Ci. Solo, 28:327-336, 2004.
RAIJ, B.van; ANDRADE, J.C.; CANTARELLA, H. \& QUAGGIO, J.A. Análise química para avaliação da fertilidade de solos tropicais. Campinas, Instituto Agronômico de Campinas, 2001. 285p.

RAIJ, B.van; CANTARELLA, H.; QUAGGIO, J.A. \& FURLANI, A.M.C. Recomendações de adubação e calagem para o Estado de São Paulo. 2.ed. Campinas, Instituto Agronômico de Campinas, 1996. 285p.

SANTOS, C.A. \& LANÇAS, K.P. Projeto e construção de um penetrômetro hidráulico-eletrônico. R. Energia Agric., 14:55-61, 1999.

SECCO, D. \& REINERT, D.J. Efeitos imediatos e residual de escarificadores em Latossolo Vermelho escuro sob PD. Eng. Agric., 16:52-61, 1997.

SILVA, I.F. \& MIELNICZUK, J. Ação do sistema radicular de plantas na formação e estabilização de agregados do solo. R. Bras. Ci. Solo, 20:113-117, 1997.

SILVA, R.H. \& ROSOLEM, C.A. Crescimento radicular de espécies utilizadas como cobertura decorrente da compactação do solo. R. Bras. Ci. Solo, 25:253-260, 2001.

TORRES, E. \& SARAIVA, O.F. Camadas de impedimento do solo em sistemas agrícolas com a soja. Londrina, Empresa Brasileira de Pesquisa Agropecuária, 1999. 58p. (Circular Técnica, 23)

TORRES, E.; SARAIVA, O.F.; PICCININ, J.L.; FARIAS, J.R.B.; GALERANI, P.R. \& GAZZIERO, D.L.P. Avaliação de sistemas de preparo do solo, rotação de culturas e semadura da soja. Londrina, Embrapa Soja, 1998 (Série Documentos)

VASQUEZ, E.V. \& DE MARIA, I.C. Influencia del Laboreo sobre la rugosidad del suelo y la retención de agua en un Ferrasol. In: CONGRESSO BRASILEIRO DE CIÊNCIA DO SOLO, 29., Ribeirão Preto, 2003. Anais. Ribeirão Preto, Sociedade Brasileira de Ciência do Solo, 2003. CD-ROM.

VERNETTI JÚNIOR, F.J. \& GOMES, A.S. Plantio direto: uma opção de manejo para a produção agrícola sustentável. Pelotas, Embrapa Clima Temperado, 1999. 69p. (Embrapa Clima Temperado. Documentos, 58)

YODER, R.E. A direct method of aggregate analysis of soils and a study of the physical nature of erosion losses. J. Am. Soc. Agric., 28:337-351, 1936.

ZONTA. E.; BRASIL, F.; GOI, S.R. \& ROSA, M.M.T. O sistema radicular e suas interações com o ambiente edáfico. In: FERNANDES, M.S., ed. Nutrição mineral de plantas. Viçosa, MG, Sociedade Brasileira de Ciência do Solo, 2006. p.7-52. 